Cuadernos de Historia Contemporánea

ISSN: 0214-400X

http://dx.doi.org/10.5209/CHCO.56273

\title{
A la nación por la clase. La campaña electoral socialista de noviembre de $1933^{1}$
}

\author{
Aurelio Martí Bataller²
}

Recibido: 11 de julio de 2016 / Aceptado: 16 de mayo de 2017

Resumen. El artículo analiza la campaña electoral realizada por el Partido Socialista Obrero Español para las elecciones de noviembre del 1933. A partir de la importancia que la nueva historia sociocultural y política atribuye a los discursos en la conformación de las identidades y la acción colectiva, el artículo intenta poner de manifiesto la capital importancia que tuvo el uso de la narrativa nacional por parte del socialismo. Con ello, se trata de llamar la atención sobre una vía central en la (re)construcción y difusión social de la identidad nacional española, como los procesos de politización y el rol que el socialismo pudo jugar a tal efecto.

Palabras clave: Segunda República; elecciones; PSOE; identidad nacional; identidad de clase.

\section{[en] To Nation trough Class. The Socialist Electoral Campaign of November 1933}

\begin{abstract}
The article deals with electoral campaign carried out by the Spanish Socialist Party for the general elections of November 1933. Starting from the importance that the new socio-cultural and political history attributed to the discourses in shaping identities and collective action, the article attempts to show the capital importance that the use of the national narrative had for socialism. In addition, by doing so, the article tries to draw attention to a central procedure in (re) construction and social dissemination of Spanish national identity, besides the processes of politicization and the role that socialism could play on it.
\end{abstract}

Keywords: II Republic; elections; PSOE; national identity; working-class identity.

Sumario. Introducción. 1. Por la clase obrera y la nación. 2. Internacionalismo y españolidad. 3. Mujeres, socialismo y nación. 4. Segunda vuelta: la construcción antifascista. 5. Conclusiones. 6. Referencias bibliográficas.

Cómo citar: Martí Bataller, A. (2017). “A la nación por la clase. La campaña electoral socialista de noviembre de 1933”. Cuadernos de Historia Contemporánea, 39, 243-265.

1 Proyecto de Investigación HAR2014-57392-P, financiado por el Ministerio de Economía y Competitividad y a través de los fondos FEDER y Grupo de investigación GVPROMETEO2016-108, GEHTID, financiado por la Generalitat Valenciana.

2 Universidad de Valencia (España)

E-mail: aurelio.marti@uv.es 


\section{Introducción}

La producción historiográfica alrededor de las elecciones durante la Segunda República cuenta con una larga trayectoria que no ha cesado de renovarse $e^{3}$. Desde los estudios inaugurales a cargo de Jean Bécarud y Javier Tusell se abrieron las puertas a numerosas investigaciones regionales, provinciales y locales centradas, fundamentalmente, en la formación de candidaturas y en los resultados electorales ${ }^{4}$. Ahora bien, no ha sido hasta fechas recientes que Roberto Villa ha llenado el vacío existente en los estudios de ámbito nacional, mediante su trabajo en torno a las elecciones de noviembre del año 1933, con la preocupación de fondo, en este caso, sobre su condición más o menos democrática 5 .

Aunque se compara con campañas anteriores y posteriores, el presente artículo toma como eje central precisamente dichas elecciones y, en concreto, la campaña realizada por el Partido Socialista Obrero Español (PSOE). En general, a pesar de la cantidad de estudios existentes, un repaso por la bibliografía existente muestra que se ha tendido a descuidar el análisis de las campañas electorales, en beneficio de otros objetos. Este parcial déficit cobra mayor importancia si se tiene en cuenta la importancia que la nueva historia sociocultural y política otorga a los discursos en la configuración de las identidades y la acción colectiva ${ }^{6}$. Desde este punto de vista, a continuación se intenta poner de manifiesto la capital importancia que tuvo el uso de la narrativa nacional por parte del socialismo y, con ello, llamar la atención sobre una vía central en la (re)construcción y difusión social de la identidad nacional española, como los procesos de politización, y el rol que pudo jugar a este respecto el PSOE.

De este modo, el artículo entiende las identidades colectivas como construcciones históricas inestables, en permanente (re)elaboración a través de los discursos, simbología y prácticas asociadas ${ }^{7}$. Mediante las narrativas sobre el nosotros, los actores sociales convertirían los sucesos en episodios de una narración mayor, la cual se erigiría en un marco cultural para interpretar la acción y procesos sociales ${ }^{8}$. Así pues, en estas páginas se considera la nación como narración y, por ende, el nacionalismo como construcción discursiva que permitiría definir el nosotros en términos de identidad nacional ${ }^{9}$. Con esta formulación es posible comprender la existencia de

3 Para un estado de la cuestión, véase Mateo, Miguel Ángel: "Fuentes y metodología para el estudio electoral de la II República", Ayer, 3 (1991), pp. 139-164; Ruiz-Manjón, Octavio: "La Segunda República española. Balance historiográfico de una experiencia democratizadora”, Ayer, 63 (2006), pp. 279-297.

4 Bécarud, Jean: La Segunda República española, Madrid, Taurus, 1967; Tusell, Javier: Las elecciones del Frente Popular en España, Madrid, Cuadernos para el Diálogo, 1971; Tusell, Javier, Ruiz, Octavio y García, Genoveva: Las constituyentes de 1931, unas elecciones de transición, Madrid, Centro de Investigaciones Sociológicas, 1982. El mismo Tusell había estudiado el ámbito madrileño en Tusell, Javier: La Segunda República en Madrid: elecciones y partidos políticos, Madrid, Tecnos, 1970.

5 Villa, Roberto: La República en las urnas. El despertar de la democracia en España, Madrid, Marcial Pons, 2011. Mientras se preparaba este artículo aparecía un nuevo trabajo sobre las elecciones de 1936, Villa, Roberto y Álvarez Tardío, Manuel: 1936. Fraude y violencia en las elecciones de 1936, Barcelona, Espasa, 2017.

6 Cruz, Rafael: "La cultura regresa al primer plano", en Rafael Cruz y Manuel Pérez Ledesma (eds.): Cultura y movilización en la España contemporánea, Madrid, Alianza, 1997, pp. 13-34; Cabrera, Miguel Ángel: "La crisis de la historia social y el surgimiento de una historia postsocial", Ayer, 51 (2003), pp. 201-224.

7 Hall, Stuart: "Who needs «identity»", en Stuart Hall y Paul Du Gay (eds.): Questions of cultural identity, Londres, Sage, 2005, pp. 1-17.

8 Somers, Margaret: "Deconstructing and reconstruting class formation theory: narrativity, relational analysis, and social theory", en John R. Hall (ed.): Reworking class, Ithaca, Cornell University Press, 1997, pp. 73-105.

9 La nación como narración fundamenta muchos de los trabajos de Stefan Berger y su grupo de investigación. Explícitamente se formula así en Berger, Stefan: "Narrating the Nation: historiography and other genres", en 
una interacción conflictiva entre discursos de nación que, desde la diversidad territorial, social, étnica y de género - variables también construidas discursivamente e inestables-, puede dar lugar a distintas versiones de la narrativa nacional en pugna por la hegemonía social y cambiantes a lo largo del tiempo.

En consecuencia, la identidad nacional se generaría a través de los discursos que sobre la nación (re)producen y difunden distintos agentes sociales. La participación en dichos discursos contribuiría a la construcción de la nación y la identidad nacional ${ }^{10}$. Por lo tanto, ¿pudo el socialismo español contribuir a la construcción y difusión social de la identidad nacional española? Si la respuesta es afirmativa, ¿cuáles fueron las vías y qué tipo de narrativa nacional impulsó? Sin duda, se trata de cuestiones arduas que requieren un gran esfuerzo y sobre las cuales apenas se podrá ofrecer aquí una aproximación.

Lo cierto es que, como hiciera ya Eric Hobsbawm, afirmar la compatibilidad entre la identidad de clase y la identidad nacional dista de suponer una novedad. No obstante, esta idea resulta frecuentemente más afirmada que practicada respecto al caso español, en el que el movimiento obrero socialista -por no hablar del anarquista- ha estado prácticamente ausente en grandes estudios sobre el proceso de construcción de la identidad nacional ${ }^{11}$. Aún más, frecuentemente se ha asociado al socialismo con una idea de nación española puramente cívica y en cierto sentido menor, en comparación con otros socialismos europeos ${ }^{12}$, cuando no con un obstáculo en la difusión social de imaginarios y narrativas nacionales ${ }^{13}$.

Frente a dichas visiones, seguidamente se intenta demostrar cómo el socialismo recurrió con normalidad a la narrativa del nacionalismo para legitimar su propuesta política, por lo que, intencionadamente o no, ofreció a su militancia un marco de significado para interpretar la realidad sobre la base de un imaginario de nación. De esta forma, el socialismo aunó las identidades de clase y nación, de manera que, al mismo tiempo que impulsaba la politización social en clave obrera, pudo contribuir a la (re)producción de una determinada idea de España.

$\mathrm{Al}$ respecto, se ha considerado especialmente adecuada la campaña electoral de finales de 1933. En aquella ocasión la participación de las mujeres y la existencia de una potente organización de masas de la derecha católica como la Confederación Nacional de Derechas Autónomas (CEDA) suponían una novedad respecto a 1931.

Stefan Berger, Linas Eriksonas y Andrew Mycock (eds.): Narrating the nation. Representations in History, Media and the Arts, Oxford, Berghan Books, 2008, pp. 1-16. La noción del nacionalismo como formación discursiva es adoptada por Calhoun, Craig: Nacionalisme, Catarroja, Afers, 2008, pp. 16-19.

10 Wodak, Ruth, et alii: The discursive formation of national identity, Edinburgh, Edinburgh University Press, 1999.

11 Únicamente se incorpora un capítulo en el caso de la monumental obra Morales, Antonio, Fusi, Juan Pablo y De Blas, Andrés: Historia de la nación y del nacionalismo español, Barcelona, Galaxia Gutenberg, 2013; mientras que no tiene una atención particular en la, por otra parte imprescindible, de Moreno, Javier y Núñez, Xosé Manoel (eds.): Ser españoles. Imaginarios nacionalistas en el siglo XX, Barcelona, RBA, 2013.

12 Guerra, Daniel: "Socialismo y cuestión nacional en la España de la Restauración (1875-1931)", Revista de Estudios Politicos, 137 (2007), pp. 183-216; del mismo autor: Socialismo español y federalismo (1873-1976), Oviedo, KRK, 2013.

13 Boyd, Carolyn P.: Historia Patria. Politica, historia e identidad nacional en España: 1875-1975, Barcelona, Pomares-Corredor, 2000; Radcliff, Pamela: "La representación de la nación. El conflicto en torno a la identidad nacional y las prácticas simbólicas en la Segunda República”, en Rafael Cruz y Manuel Pérez Ledesma(eds.): Cultura y movilización..., pp. 305-325; Holguín, Sandie: República de ciudadanos. Cultura e identidad nacional en la España republicana, Barcelona, Crítica, 2003. Una visión que apunta en un sentido contrario en Forcadell, Carlos: "Los socialistas y la nación", en Carlos Forcadell, Ismael Saz y Pilar Salomón (eds.): Discursos de España en el siglo XX, València, PUV, 2009, pp. 15-34. 
Pero, sobre todo, la concurrencia socialista en solitario singularizó las elecciones de noviembre del 1933. Estas llegaron precedidas de la salida socialista del poder a principios de septiembre, forzada por la presión de amplios sectores republicanos y con un destacable papel de Niceto Alcalá Zamora en el proceso. A partir de aquellos momentos se produjo la formación de gobiernos con pretensiones revisionistas sobre las reformas del primer bienio, lo que tras la convocatoria de nuevas elecciones generales precipitó un viraje en la estrategia política socialista. El Comité Nacional del PSOE acordó la ruptura con los republicanos en aquel mes y se abrió la vía de competencia electoral en solitario. Con Francisco Largo Caballero como principal defensor de dicha ruptura, y sin provocar todavía graves dislocaciones internas ni romper completamente con el régimen republicano, el Partido Socialista propugnó la necesidad de caminar hacia el socialismo y comprobar cuál era su fuerza social ${ }^{14}$.

La historiografía coincide en señalar la radicalización socialista en aquel proceso. Sin embargo, existen diferentes visiones sobre los ritmos y motivaciones del giro político socialista. Julio Aróstegui y Santos Juliá han observado que sería en septiembre, a partir de la ruptura de la alianza con los republicanos, cuando se daría el pistoletazo de salida a la radicalización de los planteamientos políticos socialistas ${ }^{15}$. En cambio, José Manuel Macarro y Fernando del Rey, entre otros, entienden que el cambio fundamental se dio desde la derrota electoral, la cual provocaría el final de la adhesión republicana socialista -que, en su opinión, más que adhesión sería una concepción patrimonialista ${ }^{16}$. Compartiendo parcialmente las dos visiones, Sergio Valero ha subrayado la importancia de las bases del socialismo en aquella radicalización, en marcha ya desde finales de $1932^{17}$. Finalmente, Sandra Souto y Paul Preston han insistido en la importancia del contexto internacional en la estrategia política del socialismo español ${ }^{18}$.

Por consiguiente, más allá de los distintos matices en la interpretación, se constata la búsqueda del propio espacio político, diferenciado del burgués, por parte del socialismo, lo que atribuye a estas elecciones un interés especial. Por lo tanto, la campaña electoral supone un campo idóneo para comprobar los referentes invocados por el PSOE con la finalidad de dar cuenta de la lectura de la identidad colectiva, del nosotros, que se potenciaba desde la cultura política socialista. Igualmente, el análisis comparativo con el discurso socialista durante las campañas electorales del resto del período republicano permite reforzar la hipótesis de la capitalidad de la narrativa nacional en la estrategia y el lenguaje político socialista. Seguidamente, se ofrece un estudio organizado por distintos bloques temáticos alrededor de los cuales se articuló la propaganda política socialista.

14 Casanova, Julián: República y guerra civil, Barcelona, Crítica/Marcial Pons, 2007; Juliá, Santos: Los socialistas en la política española, 1879-1982, Madrid, Taurus, 1997.

15 Aróstegui, Julio: Largo Caballero. El tesón y la quimera, Barcelona, Debate, 2013, pp. 301-336. Juliá, Santos: Los socialistas en..., pp. 196 y ss.

16 Macarro, José Manuel: "Causas de la radicalización socialista en la II República”, Revista de Historia Contemporánea, 1 (1982), pp. 178-226; del mismo autor: "Los socialistas y la revolución”, en Manuel Álvarez Tardío y Fernando del Rey (eds.): El laberinto republicano. La democracia española y sus enemigos (19311936), Barcelona, RBA, 2012, pp. 75-100; del Rey, Fernando: "La República de los socialistas", en Fernando del Rey (dir.): Palabras como puños. La intransigencia política en la Segunda República española, Madrid, Tecnos, 2011, pp. 158-225.

17 Valero, Sergio: Republicanos con la monarquía, socialistas con la República. La Federación Socialista Valenciana durante la Segunda República y la Guerra Civil (1931-1939), València, PUV, 2015.

18 Souto, Sandra: "De la paramilitarización al fracaso: las insurrecciones socialistas de 1934 en Viena y Madrid", Pasado y Memoria. Revista de Historia Contemporánea 2 (2003), pp. 193-220; Preston, Paul: La destrucción de la democracia en España, Barcelona, Grijalbo Mondadori, 1978. 


\section{Por la clase obrera y la nación}

La batalla electoral del momento, y así lo entendieron y aceptaron los socialistas, constituía una pugna entre el marxismo y el antimarxismo, una lucha de socialistas contra la burguesía y sus agrupaciones "fascistas"19. Todo eso, sin duda, significó una transformación cualitativa de los discursos respecto a anteriores ocasiones. Las elecciones de abril y junio de 1931 estuvieron dominadas, especialmente las primeras, por la disyuntiva entre Monarquía y República, mientras que en las municipales parciales de 1933 se consideraron una evaluación del apoyo a la gestión de la coalición gobernante republicana y socialista.

Por lo tanto, diferentes autores han considerado que los socialistas realizaron una campaña electoral bajo los símbolos de la lucha de clases y la revolución ${ }^{20}$. Así, Villa observa que el PSOE asumió el rol de partido marxista para marginar al resto de fuerzas de izquierda y que, con ello, apostó por la idea de caminar aceleradamente hacia el socialismo ${ }^{21}$.

Sin pretender negar que eso se produjera, un análisis en profundidad muestra que esta dinámica fue totalmente compatible con el despliegue de una retórica impregnada de connotaciones nacionales de signo español. Es decir, si la derecha se presentó en bloque a las elecciones bajo la bandera de la defensa de la patria y la religión, elementos cuasi inseparables en sus discursos -lo que no ha escapado a ningún analista $^{22}$, la respuesta socialista se pudo articular de forma similar. Efectivamente, la voluntad decidida de combatir a los enemigos de clase no habría de eliminar la posibilidad de que el socialismo se presentara como defensor de la auténtica nación española frente a los malos patriotas y antiespañoles que, al fin y al cabo, identificaban con los sectores de la derecha política y católica y con terratenientes, burgueses y capitalistas.

Así pues, un argumento central en la campaña socialista fue la caracterización del socialismo como defensor y representante de la verdadera España. Esto se explicitó el 18 de octubre, cuando El Socialista reclamó urgentemente la aceleración de la campaña electoral de acuerdo con la línea editorial del diario y las indicaciones enviadas a los propagandistas ${ }^{23}$. En aquel número se conminaba a las agrupaciones a formar candidaturas con probados socialistas que pudieran facilitar la victoria, "sin olvidar, naturalmente, que nuestro Partido es nacional y en ningún caso provincial ni regional". Una advertencia dirigida a seguir fielmente las premisas del partido que se completaba con la certeza de que las agrupaciones actuarían según los intereses permanentes del partido. Pero,

¿Y los intereses permanentes de España?, se nos preguntará. Y la respuesta es ésta: están vinculados a los de nuestro Partido. Así, como lo leen nuestros lectores:

19 Entre otros, "Las banderas para las elecciones", El Socialista, 11 de octubre de 1933 y “Aceptación gustosa de una división”, El Socialista, 13 de octubre de 1933.

20 Tusell, Javier: La Segunda República..., pp. 98-99; Forner, Salvador: Industrialización y movimiento obrero. Alicante 1923-1936, València, Alfons el Magnànim, 1982, pp. 344-347; Andreu, Mariano: Alicante en las elecciones republicanas. 1931-1936, Alicante, Universidad de Alicante, 1985, pp. 144-149.

21 Villa, Roberto: La República en..., pp. 220-222.

22 Por ejemplo, del Rey, Fernando: Paisanos en lucha. Exclusión politica y violencia en la Segunda República española, Madrid, Biblioteca Nueva, 2008, pp. 310 y ss.; Villa, Roberto: La República en..., p. 254.

23 "En campaña por el partido", El Socialista, 18 de octubre de 1933. 
vinculados a los intereses de nuestro Partido (...). No acertamos a imaginarnos a nuestro país de otra suerte que modelado con arreglo a nuestras doctrinas. Recreado con ellas. Si necesitásemos explicar cosa tan obvia diríamos que nuestra adscripción al Socialismo está determinada, en muy buena parte, por la evidencia de que en España coexisten, sin posibilidad de inteligencia, en lucha permanente, dos Españas. La que representamos nosotros y la que representan quienes se han declarado sin que necesitásemos de su declaración, nuestros enemigos. Su España jamás será la nuestra.

Según se observa, los socialistas proclamaban inequívocamente la inextricable unión existente entre el socialismo y una determinada visión de la nación española. El PSOE y los intereses permanentes de la nación estaban íntimamente ligados, hasta el punto de que la adscripción al socialismo era consecuencia de la existencia de dos Españas opuestas: la suya y la de sus enemigos. Luego, la militancia en las filas socialistas venía marcada por la voluntad de defender y materializar una idea de España.

El artículo continuaba para aclarar que los socialistas buscaban

La España proletaria a la que podamos entregar nuestros entusiasmos ardientes. Estamos convencidos de que encontraremos esa España anhelada. Por eso luchamos, por eso no tenemos inconveniente en desafiar todos los obstáculos que se oponen a nuestra victoria. ¿Qué España es ésa? La que hacen con sus manos, a diario, los metalúrgicos en sus factorías, los mineros en sus minas, los pescadores en sus embarcaciones, los campesinos en los campos, los químicos en sus laboratorios, los matemáticos en sus gabinetes... En suma: la España de fisonomía trabajadora. Esa es la nuestra y la que buscamos ansiosamente desde el mismo momento de nacer como partido político y como organización obrera ${ }^{24}$.

De este modo, por un lado, la lucha socialista tenía un objetivo eminentemente nacional, ya que la misma organización política del PSOE perseguía la realización de la verdadera nación española. Por otro lado, esa nación se definía por su contenido obrerista, por su condición de patria de los trabajadores. En consecuencia, el obrerismo no discutía la idea de nación, sino que la articulaba y se situaba en su centro.

La salvación de la auténtica nación había sido ya un argumento de peso durante las campañas electorales de 1931. El manifiesto conjunto de PSOE y UGT de marzo de aquel año llamaba a las urnas para rechazar al régimen monárquico y establecer la República, "suprema aspiración de la mayoría del pueblo español" y "salvación del país" "25. Entonces se cargaban las tintas contra la Monarquía, a la cual se responsabilizaba de los males patrios, por lo que se afirmaba que "para que España viva y progrese es necesario que desaparezca la monarquía"26. Los Borbones eran considerados una "dinastía extranjera" que trataba a España como país conquistado y se debía acabar con ella por el honor y la dignidad nacional ${ }^{27}$. La misión profundamente nacional del socialismo fue subrayada por Francisco Largo Caballero al afirmar que

24 Todas las citas extraídas de "Solo hay que conquistar uno, solo uno", El Socialista, 18 de octubre de 1933. Este artículo apareció en otras publicaciones como Acción Socialista (La Coruña), 23 de octubre de 1933.

25 "Partido Socialista y Unión General de Trabajadores", El Socialista, 24 de marzo de 1931.

26 Cartel electoral aparecido en p. 4 de El Socialista, 2 de abril de 1931.

27 "Por el honor de España", El Socialista, 25 de marzo de 1931. 
"por encima de todos los intereses está el de la patria; porqué también nosotros amamos la patria" 28 .

Igualmente, aquella perspectiva continuó presente en las elecciones a Cortes de aquel año. En dicha ocasión, Luis Araquistáin señaló la necesidad de separar Iglesia y Estado para evitar que la primera constituyera un "Estado dentro del Estado nacional", mientras insinuaba que toda alternativa a la República desembocaría en una intervención extranjera sobre España. Por todo ello, equiparaba votar socialista y republicano a "votar por la salvación de España"29. Asimismo, a pesar de que el contexto político de 1931 podía favorecer la moderación socialista, el Partido Socialista no olvidó su objetivo final y recordó que asumiría su responsabilidad y activaría la vocación revolucionaria "si las circunstancias lo aconsejan, para la salvación de España y del Socialismo" "30.

Como en 1933, a principios de la década de 1930 el PSOE identificaba su proyecto político con la defensa y regeneración de España, al mismo tiempo que la situaba en un lugar destacado del debate político. Esta dinámica tomó gran fuerza en 1936, cuando el socialismo se propuso explícitamente arrebatarle a la derecha la invocación de la nación: "que no se llamen valedores de la patria. Dejen el nombre de España quieto" 31 . En efecto, en el marco de la nueva coalición del Frente Popular, el socialismo se aplicó al extrañamiento del adversario de la comunidad nacional ${ }^{32}$.

Tal como se podía leer en los eslóganes electorales propuestos por la izquierda socialista: “ESPAÑA SOMOS NOSOTROS. ¡LOS TRABAJADORES!”; “¿Español! ¡Vota por el Frente de izquierdas! ¡Es votar por España!”33. Por su parte, también el prietismo enfatizó la españolidad del Frente Popular, lo que llevó a Fernando de los Ríos a considerar al proletariado "la misión biológica de la posibilidad de España", a defender la España de los trabajadores, la cultura y la justicia y a presentar las elecciones del 16 de febrero como una disyuntiva entre la perdición y la salvación nacional. Igualmente, en su conocido discurso de Cuenca, Prieto confesaba sentir España hasta en el tuétano de sus huesos y afirmaba la devoción y compromiso frentepopulista con respecto a la nación ${ }^{34}$. De esta forma, durante la campaña de 1936, ambas facciones del socialismo coincidieron en tratar de apropiarse la idea de España y en describir las elecciones como un conflicto por la nación y su futuro ${ }^{35}$. El conjunto del Partido Socialista, así, se pudo erigir en agente difusor del discurso y la simbología nacional española, interpretada y asumida siempre desde su cultura política.

En 1933, aquella identificación plena entre nación española y movimiento socialista desempeñó un rol fundamental, como se habría puesto de manifiesto ya en

28 "En el teatro Maravillas", El Socialista, 7 de abril de 1931. Véase también en la misma edición "La lucha contra la reacción y el absolutismo".

29 Las citas de Araquistáin en "Un interesante discurso de Luis Araquistáin”, El Socialista, 28 de junio de 1931.

30 "Hasta dónde llegaremos si es preciso", El Socialista, 28 de junio de 1931.

31 "Dejad a España quieta", El Socialista, 21 de enero de 1936.

32 Estrategia detectada para aquellas elecciones por Cruz, Rafael: En el nombre del pueblo. República, rebelión y guerra en la España de 1936, Madrid, Siglo XXI, 2006, pp. 88-89.

33 Eslóganes aparecidos en Claridad, 25 de enero de 1936 y reproducidos por otras publicaciones como El Obrero (Elche), 2 de febrero de 1936.

34 De los Ríos en "Un gran mitin en Córdoba, con intervención de Martínez Barrio y Fernando de los Ríos", El Socialista, 9 de febrero de 1936. Para el discurso de Cuenca Prieto, Indalecio: Siento a España..., S. 1., Ediciones La Motorizada, 1938.

35 Martí, Aurelio: "España somos nosotros. Socialismo y democracia republicana: las elecciones de 1936", en Ana Aguado y Luz Sanfeliu (eds.): Caminos de democracia. Ciudadanías y culturas democráticas en el siglo XX, Granada, Comares, 2014, pp. 45-61. 
la inauguración oficial de la propaganda electoral en el cine Europa de Madrid. En aquella ocasión, Largo acusó a los republicanos de no respetar los pactos contraídos con los socialistas, apuntó que la toma del poder por parte socialista sería por la vía legal, o por otras en caso de no ser posible, y justificó su labor en el Ministerio de Trabajo. En este sentido, el líder socialista subrayó que la legislación de su ministerio habría pretendido defender los intereses de los trabajadores y que con ello, contrariamente a lo que se decía desde la oposición, no se perjudicaba a la nación. De hecho, se preguntaba retóricamente,

¿Cuál es el interés nacional? ¿El interés nacional es simplemente el interés de los capitalistas? ¿Es que los trabajadores no forman parte de la nación? ¿Es que la mayoría de la nación no la constituye la masa trabajadora? ¿Si se mejoran las condiciones del trabajo no se hace una política nacional?

Además, concretamente sobre el seguro de maternidad, comentó que

El capitalismo y sus defensores aluden a su amor a la raza y creen que trabajan intensamente por el robustecimiento de la raza española señalando un día de fiesta al año: el Día de la Raza. Hemos tenido que ser los socialistas lo que nos hayamos preocupado de fortalecer esa raza con las medidas que acabo de narrar (...). ¿En beneficio de quién? En beneficio de la modesta obrera, en beneficio de sus hijos, en beneficio de la raza, en beneficio, en fin, de la nación entera ${ }^{36}$.

Así pues, hacer política a favor de los trabajadores equivalía a defender el interés nacional, pues estos eran la mayoría de la nación. Asimismo, si alguien se habría preocupado por la "raza española", significativamente robustecida a partir de la atención a la función reproductiva de las mujeres, eran los socialistas y no los capitalistas.

Días después, en Azuaga (Badajoz) Largo insistió en los mismos puntos. Su discurso, según Villa prueba de las tendencias antidemocráticas del PSOE, indicaba la existencia de la lucha de clases y la unión de las fuerzas burguesas contra el proletariado. La democracia republicana burguesa no habría comportado la realización de la libertad, la igualdad y la fraternidad, que únicamente se daría en el régimen socialista. Ese debía ser el objetivo a perseguir en las elecciones, o más allá ${ }^{37}$. Ahora bien, el ex ministro también apuntaba que, derrocado el mito de la República como salvación de los trabajadores, era necesario activar la conciencia de clase para entender también que el proletariado representaba el auténtico interés nacional, que este estaba "estrechamente vinculado al interés de los productores", y que "los Gobiernos que quieran defender el interés nacional deben velar ante todo por el nivel de vida de la clase trabajadora" ${ }^{38}$. Por tanto, la defensa de los intereses de los trabajadores implicaba la de los nacionales, y a la inversa.

De esta forma, la propaganda electoral socialista ponía en el centro del debate político la defensa de la nación española, idea a la cual el PSOE pretendía aparecer asociado ante la población -como habría sucedido en 1931 y sucedió posteriormente en 1936. Esto no implicaba -no tenía por qué hacerlo- la desaparición del componente

36 Ambas citas de "Tres grandes discursos y un entusiasmo indescriptible", El Socialista, 21 de octubre de 1933.

37 Villa, Roberto: La República en..., pp. 228-229.

38 "Otro gran discurso de Largo Caballero", El Socialista, 10 de noviembre de 1933. 
obrerista del discurso socialista. Al contrario, el obrerismo se insertaba en el centro de la comunidad nacional imaginada, por lo que el socialismo, en tanto que movimiento que pugnaba por la mejora de la situación de los obreros, se consideraba legitimado para ostentar la representación de los intereses de España.

Ahora bien, situado en este punto, el Partido Socialista podía transgredir la estricta apelación al voto obrero para llamar a la movilización del conjunto de la población. En este sentido, Araquistáin opinaba que el PSOE era el único capaz de solucionar los problemas económicos españoles porque, precisamente, "solo un partido verdaderamente nacional como el socialista" podía imponer "el interés nacional al particularismo anárquico de los intereses individuales o locales". Los egoísmos particulares de los aristócratas invalidaban la opción monárquica, mientras que los republicanos no pasaban de ser "prisioneros de intereses locales (...) [y] regionales" 39 .

Por ello, el cántabro reclamaba el voto de la clase media, de los técnicos e intelectuales que el próximo régimen socialista requeriría con la finalidad de que "no se vea obligado a solicitar la colaboración de los técnicos extranjeros". Si las clases medias técnicas procedían así, serían "mejores españoles, más atentos al interés nacional". Estas debían acudir al Partido Socialista, junto a los trabajadores manuales, para crear "una nación más justa, más culta, más rica y más respetada en los consejos del mundo"; no podían "votar por la España agotada de ayer, por la España feudal, monárquica y teocrática que le brindan las derechas". Al contrario, debían confiar su voto "a la España vital de mañana, a la España socialista, que será al mismo tiempo la España inmortal" ${ }^{\prime 40}$.

Estos discursos apuntan a un intento de movilización interclasista sostenido con argumentos basados en la narrativa nacional. Una vía fundamental en dicha operación sería la apelación al referente popular. Al respecto Fernando del Rey ha observado que el socialismo hizo frente a la campaña de la derecha mediante una estrategia que empleaba un lenguaje interclasista articulado alrededor del pueblo honrado ${ }^{41}$. Como muestra, un gran titular de portada del rotativo socialista de Puenteareas (Pontevedra) afirmaba "solo hay un poder, el vuestro, el poder del pueblo. Si quieres ser poder, pueblo"42.

Ciertamente, el creciente protagonismo del referente popular en el vocabulario socialista dataría, como mínimo, de principios del siglo XX, a partir del estrechamiento de contactos con el republicanismo ${ }^{43}$. En los momentos del establecimiento de la Segunda República, el pueblo ya formaba parte de los discursos del socialismo español y este contribuyó, junto al resto de fuerzas políticas antimonárquicas, a situar al sujeto popular en el centro de la legitimidad política e intentó apropiarse su representación ${ }^{44}$. Este recurso fue una constante a lo largo del período republicano y durante la campaña electoral de 1936 la fórmula del Frente Popular contribuyó a su continuidad, pues habilitaba el uso de un vocabulario que unía pueblo, república y nación ${ }^{45}$.

39 Todas las citas en "Una política interior y exterior", El Socialista, 15 de noviembre de 1933. Énfasis mío.

40 Todas las citas en "La clase media y el Socialismo", El Socialista, 19 de noviembre de 1933.

41 del Rey, Fernando: Paisanos en lucha..., pp. 320-323.

42 "Solo hay un poder, el vuestro, el poder del pueblo. Si quieres ser poder, pueblo", Renovación (Puenteáreas), 31 de octubre de 1933 .

43 Entre otros, Juliá, Santos: "Un dualismo problemático. La herencia de Pablo Iglesias", Anthropos. Boletín de información y documentación, 45-46-47. Extraordinario 6 (1985), pp. 176-180; Elorza, Antonio y Ralle, Michel: La formación del PSOE, Barcelona, Crítica, 1989, pp. 332-338.

44 Cruz, Rafael: Una revolución elegante. España, 1931, Madrid, Alianza Editorial, 2014.

45 Godicheau, François: 'L'existence et le nom du Front populaire comme enjeux d'interprétation et d'appropriation (1936-1938)", Mélanges de la Casa de Velázquez, 41 (2011), pp. 17-35; del mismo autor: "Front Populaire, de 
Respecto a la campaña electoral de 1933, la agrupación socialista de Mahón lanzó un manifiesto que recordaba a los votantes que la candidatura socialista era "la del pueblo, del verdadero pueblo que trabaja y sufre, del pueblo que se afana y lucha por un mejor bienestar, que pide leyes beneficiosas para el país"; mientras que el resto representaba a "los negociantes que chupan la sangre del pueblo, viviendo y engordando a costa de éste" ${ }^{46}$. Por consiguiente, frente a los socialistas, "el verdadero pueblo", no había más que egoísmos, intereses y privilegios ${ }^{47}$.

Sin embargo, esta retórica no dibujaba únicamente un conflicto político entre la comunidad popular moralmente superior y excluida del poder político por sus enemigos, sino que la dicotomía se connotaba nacionalmente. Aunque las apelaciones populistas entre los socialistas pudieran teñirse de significados clasistas y revolucionarios $^{48}$, esto no supondría una asepsia nacional. Hay que recordar que entre los sectores intelectuales y políticos izquierdistas se construyó un populismo como expresión de las esencias políticas y culturales españolas y garantía de continuidad y regeneración nacional, que se pretendía alternativo a las versiones conservadoras de la identidad nacional española ${ }^{49}$. Por lo tanto, no fueron extrañas entre los socialistas las llamadas al voto al grito de "¡Por España, por el pueblo auténtico!"50.

En resumen, ya fuera mediante la dualidad pueblo/poderosos o a través del binomio proletariado/burguesía, en todo momento la lucha política se envolvía de una dimensión nacional. La propaganda socialista se esforzó por diseñar la existencia de un conflicto nacional, una oposición entre la auténtica España y los intereses particulares de los sectores que no representaban a la nación. Se pretendía demostrar que el voto para los socialistas era un voto fiel a la patria, por el "decoro" de España ${ }^{51}$. El discurso socialista unía la lucha e identidad de clase a la nacional, de manera que la militancia podía recibir la idea de que la socialista era, ya no una, sino la mejor y más fiel expresión de la españolidad. El socialismo (re)elaboraba, se apropiaba y difundía una narración de la nación que le permitía ejercer de portaestandarte de la identidad y los intereses nacionales, sin por ello abandonar su condición de defensor de la clase trabajadora.

\section{Internacionalismo y españolidad}

Según se trata de señalar, el Partido Socialista insistió en disputar las elecciones en el terreno de juego de la nación, sin por ello marginar los referentes de su cultura política. Entre estos destacaría el internacionalismo, elemento que impregnó su narrativa

la tactique cominternienne aux «politiques du peuple»", Bulletin d'Histoire Contemporaine de l'Espagne, 48 (2013), pp. 13-25.

46 "Manifiesto del Partido Socialista Obrero - Agrupación de Mahón”, Justicia Social (Mahón), 4 de noviembre de 1933.

47 “iA triunfar camaradas!”, Justicia (Linares), 4 de noviembre de 1933.

48 Álvarez Junco, José: "En torno al concepto de «pueblo». De las diversas encarnaciones de la colectividad como sujeto político en la cultura política española contemporánea", Historia Contemporánea, 26 (2004), pp. 83-94.

49 Entre otros, Mainer, José Carlos: La Edad de Plata (1902-1939). Ensayo de interpretación de un proceso cultural, Madrid, Cátedra, 1986; Fuentes, Víctor: La marcha al pueblo en las letras españolas: 1917-1936, Madrid, Ediciones de la Torre, 2006; Cobb, Cristopher H.: La cultura y el pueblo: España, 1930-1939, Barcelona, Laia, 1981. Para el caso comunista, Cruz, Rafael: El arte que inflama. La creación de una literatura política bolchevique en España. 1931-1936, Madrid, Biblioteca Nueva, 1999.

50 "Nuestra última arenga", ;Adelante! (Teruel), 18 de noviembre de 1933.

51 “Hay que votar al socialismo. ¡Por el decoro de España!”, El Socialista, 19 octubre de 1933. 
nacional. En efecto, aunque esta cuestión sobrepasa las dimensiones del presente artículo, es necesario subrayar que el referente internacionalista se integró como elemento propio del discurso nacional de la cultura política socialista. En este aspecto el PSOE participó de una construcción compartida con el resto de socialismos europeos provenientes de la Segunda Internacional, los cuales hicieron del internacionalismo obrero una vía para tratar de apartarse de todo atisbo de chovinismo, pero, al mismo tiempo, sostener su vinculación a la nación y denunciar la falta de patriotismo del resto de opciones políticas. Todo ello, además, sin renunciar a su condición de movimiento obrero inserto en la tradición marxista ${ }^{52}$. De este modo, el internacionalismo socialista no se opuso a la nación como ente político y cultural, ni negó la existencia de genios y tradiciones nacionales distintivas, en relación con las cuales el socialismo tendió a equiparar sus posiciones políticas.

En el caso español, el Partido Socialista articuló armónicamente internacionalismo obrero y defensa de una idea de España a lo largo del período republicano ${ }^{53}$. A diferencia de las campañas electorales posteriores, durante 1931 dicha construcción apenas fue enarbolada. No obstante, en aquel momento Largo indicó que el triunfo sobre la Monarquía supondría contribuir a la muerte del fascismo en Europa, por lo que la lucha socialista adquiría una dimensión internacional compatible con la citada afirmación de la preponderancia de los intereses de España por encima de todo ${ }^{54}$.

En cambio, para noviembre de 1933 los socialistas remarcaron el celo con que, manteniendo su internacionalismo, defendían los intereses y características nacionales. Así, en el acto de inauguración de la campaña electoral, Fernando de los Ríos llamó a la lucha anticapitalista, contra la injusticia feudal y el catolicismo belicoso. Pero, el llamamiento lo realizó no tanto como socialista, sino como "español, y en nombre de España, de la España de todos y de la España eterna". De esta manera, el malagueño intentaba destacar, frente a quienes entendían el "internacionalismo como opuesto al nacionalismo", que los socialistas eran conscientes que "ni en la Humanidad desembocamos sino como españoles en cuanto a individuos y como elementos colectivos en cuanto formamos parte de una nación". Los socialistas debían atender fundamentalmente "los problemas de nuestro pueblo", por lo que desde el gobierno habrían procurado que "España sea una unidad de vida dentro del organismo histórico y del humano", porque "concebíamos la nación como una personalidad cultural" 55 . Por lo tanto, la participación de la doctrina internacionalista no restaba un ápice de lealtad nacional al socialismo, el cual pretendería perpetuar la existencia de la personalidad cultural española.

En una dirección similar, Luis Jiménez de Asúa proclamó en Almendralejo (Badajoz) que el socialismo no colaboraría ya con ningún gobierno republicano, sino que su objetivo era alcanzar el poder para preparar la revolución social que colmaría

52 Imprescindible al respecto Winock, Michel: (1973) "Socialisme et patriotisme en France (1891-1894)", Revue d'Histoire Moderne et Contemporaine, 20 (1973), pp. 376-423; Berger, Stefan y Smith, Angel: "Between Scylla and Charybdis: nationalism, labour and ethnicity across five continents, 1870-1939”, en Stefan Berger y Angel Smith (eds.): Nationalism, Labour and ethnicity 1870-1939, Manchester, Manchester University Press, 1999, pp. 1-30; Callahan, Kevin: "Performing Inter-Nationalism in Stuttgart in 1907: French and German Socialist Nationalism and the Political Culture of an International Socialist Congress", International Review of Social History, 45 (2000), pp. 51-87. Especialmente interesante resulta el trabajo de Ward, Paul: Red Flag and Union Jack. Englishness, patriotism and the British left, 1881-1924, Rochester, The Boydell and Brewer Ltd, 1998.

53 El autor ha tratado el caso del PSOE en 2016 y en prensa.

54 "En el teatro Maravillas", El Socialista, 7 de abril de 1931.

55 Todas las citas en "Tres grandes discursos y un entusiasmo indescriptible", El Socialista, 21 de octubre de 1933. 
las aspiraciones obreras. Sin embargo, frente a las acusaciones de falta de patriotismo enunció que los socialistas eran "internacionalistas, pero no antipatriotas, pues la patria no es el idioma, ni las leyes, ni las costumbres, ni las fronteras, sino un paisaje que se lleva en el alma"56.

Proclamada la fidelidad internacionalista y nacional española, el socialismo atacó a la burguesía capitalista y a las derechas por falta de auténtico patriotismo. Así, Carlos Hernández recalcó que los problemas económicos republicanos provenían de la política de Miguel Primo de Rivera, quien habría entregado España "a los monopolios extranjeros y (...) congregaciones religiosas" $"$. Igualmente, El Socialista ya había denunciado que, mientras el primer gobierno republicano habría resistido el sitio del capital extranjero y nunca habría pensado en reducir la "escasa independencia" española, Diego Martínez Barrio vendía "parte de nuestro suelo a dos Compañías extranjeras". Aquella operación supondría la continuidad de la política de la Monarquía, la cual "metió a los ingleses y a los franceses en España con las concesiones mineras", y la Dictadura, que "hipotecó nuestras comunicaciones, estrangulando nuestra libertad nacional al entregar los teléfonos a los yanquis"

Sobre este punto volvieron Largo, en un mitin en Jaén, y Araquistáin, en Madrid. El madrileño destacó que España tenía recursos y medios suficientes para salir adelante sin la intervención de compañías extranjeras, cuya presencia se habría rehusado desde el gobierno anterior porque supondría "entregarse al capitalismo de otros países", lo que consideraba una forma de conquista. Largo lo tenía claro: "nosotros somos más patriotas que ellos porque trabajamos en España, dejamos aquí el sudor de nuestra frente. Y, sin embargo, ellos se llevan el producto de nuestro trabajo al extranjero" 59 .

Por su parte, el cántabro proclamó que la derecha católica pertenecía a "siniestros organismos internacionales: la Compañía de Jesús y la Iglesia de Roma”. En cambio, los socialistas

No quiere[n] suprimir las naciones en tanto son resultado de la Naturaleza (...). Somos quizá más españoles que los demás españoles, porque por nuestra sensibilidad y nuestro destino, vinculado a la clase trabajadora, sentimos como nadie sus miserias. Queremos crear una nación y acabar con las clases. Y que fuera de la nación, la cooperación internacional acabe con la división entre naciones burguesas y proletarias ${ }^{60}$.

Por lo tanto, Araquistáin ubicaba las naciones en el plano de los elementos naturales, frente a los cuales, en consecuencia, el socialismo no pretendería -ni podríaactuar. Al contrario, según su razonamiento, la españolidad socialista era mayor a causa de su ligazón a los destinos de los trabajadores, nuevamente asociados al núcleo nacional. Así, el objetivo socialista se situaba en la realización definitiva de la nación mediante la abolición de las clases para poder estrechar una cooperación

\footnotetext{
56 "Jiménez Asúa dice en Almendralejo que la Revolución social es la única que llenará las aspiraciones obreras", El Socialista, 16 de noviembre de 1933.

57 "La campaña electoral", El Socialista, 2 de noviembre de 1933.

58 Las citas sobre dicha operación se extraen de "Concesiones a entidades extranjeras", El Socialista, 27 de octubre de 1933.

59 "El importante acto socialista de Jaén”, El Socialista, 7 de noviembre de 1933.

60 "Nuestra victoria de mañana", El Socialista, 18 de noviembre de 1933.
} 
internacional alejada de relaciones de poder. Estas proclamas, por cierto, abundan en la idea formulada por Jean Jaurès de acuerdo con la cual "only socialism (...) will resolve the antagonism of classes and make of each nation, finally at peace internally, a particle of humanity" 61 .

Inversamente, el intelectual socialista destacaba la falta de lealtad a España, a su soberanía y economía, mostrada por la coalición antimarxista, lo que ejemplificaría el servilismo hacia la Iglesia de Roma y el capitalismo internacional extranjero. Consecuentemente, afirmaba contundente en otro acto que

El antimarxismo nos combate, no porque los socialistas españoles obremos al dictado de ningún poder extraño, que no existe sobre nosotros, pues en nuestra Internacional la autonomía de las Secciones nacionales es absoluta, sino porque no queremos que España, como Estado, sea tributaria y espiritualmente vasalla de un Estado extranjero, que es la Iglesia.

Si hay aquí un partido extranjerizante y antiespañol son las derechas. No nos hablen a tontas y a locas, de su españolismo que les viene de Roma. Y si hay un Partido profundamente nacional, no en contradicción con nuestro internacionalismo, sino en concordancia con nuestro internacionalismo y como base suya, históricamente ineludible, es el Socialista ${ }^{62}$.

La españolidad de los proyectos políticos parecía pues una cuestión de vital importancia para el socialismo. Tanto es así que con anterioridad a las elecciones, El Socialista ya había criticado la formación de Acción Católica por "injerirse en la vida española unificada y dirigida por una potestad que no es de España" y recibir "inspiraciones y direcciones extrañas para operar en España y sobre voluntades españolas"63.

Además, a diferencia del internacionalismo marxista, según explicaba Julián Besteiro en el cine Pardiñas, el "cosmopolitismo aristocrático" renegaba "de su raza", era "indiferente a su país" y, frecuentemente, renunciaba a la propia lengua ${ }^{64}$. De hecho, aunque fuera del período electoral, los socialistas explicitaron como el internacionalismo obrero no implicaba el abandono de las características nacionales ya que el "internacionalismo no es un páramo, sino un jugoso paisaje en que concurren genios de todas las patrias, cada uno con su literatura, su música, sus visiones étnicas" $"$.

Posteriormente, el inter-nacionalismo patriótico socialista reapareció en la campaña electoral de 1936, tanto para denunciar la traición nacional de las derechas, como para afirmar la lealtad española del Partido Socialista y el Frente Popular ${ }^{66}$. A tal efecto, paradigmáticas fueron sendas intervenciones del momento a cargo de De los Ríos y Prieto. Ambos negaron el calificativo de Anti-España y, al tiempo, subrayaron su españolidad e internacionalismo. El malacitano se confesó español "hasta las cachas" y afirmó contra la derecha que "España es lo que nosotros representamos.

61 Citado en Holbraad, Castern: Internationalism and Nationalism in European Political Thought. Nueva York, Palgrave Macmillan, 2003, p. 142.

62 "El frente único del capitalismo", El Socialista, 9 de noviembre de 1933.

63 "La Acción Católica", El Socialista, 15 de febrero de 1933.

64 "El acto del domingo en el cine Pardiñas", El Socialista, 7 de noviembre de 1933.

65 "La vuelta a nuestros clásicos", El Socialista, 24 de abril de 1936.

66 Sobre el primer elemento véase “AArriba España?”, La Lucha de Clases, 24 de enero de 1936 y “Que no nos salve Gil ni nos renueve Calvo", El Socialista, 28 de enero de 1936. 
España es lo que nosotros pensamos"67. Mientras, Prieto realizó su particular profesión de fe españolista en Cuenca y argumentó la devoción españolista del Frente Popular y su condición de representante de la patria ${ }^{68}$.

En conjunto, el componente obrero internacionalista no alejó al socialismo de la narrativa nacional. Contrariamente, este elemento propio de la cultura política socialista mostraría la capacidad de (re)producción e interpretación del lenguaje nacional desde la diversidad. En la participación de los discursos de España, el socialismo actuó desde las herramientas conceptuales que configuraban sus marcos de referencia e identidad. Por todo ello pudo convertirse en un activo agente de construcción y difusión de una narración de la nación. La clase y la nación no suponían elementos irreconciliables como bien sintetizaba el cartel electoral ofrecido por El Socialista el 1 de noviembre de 1933:

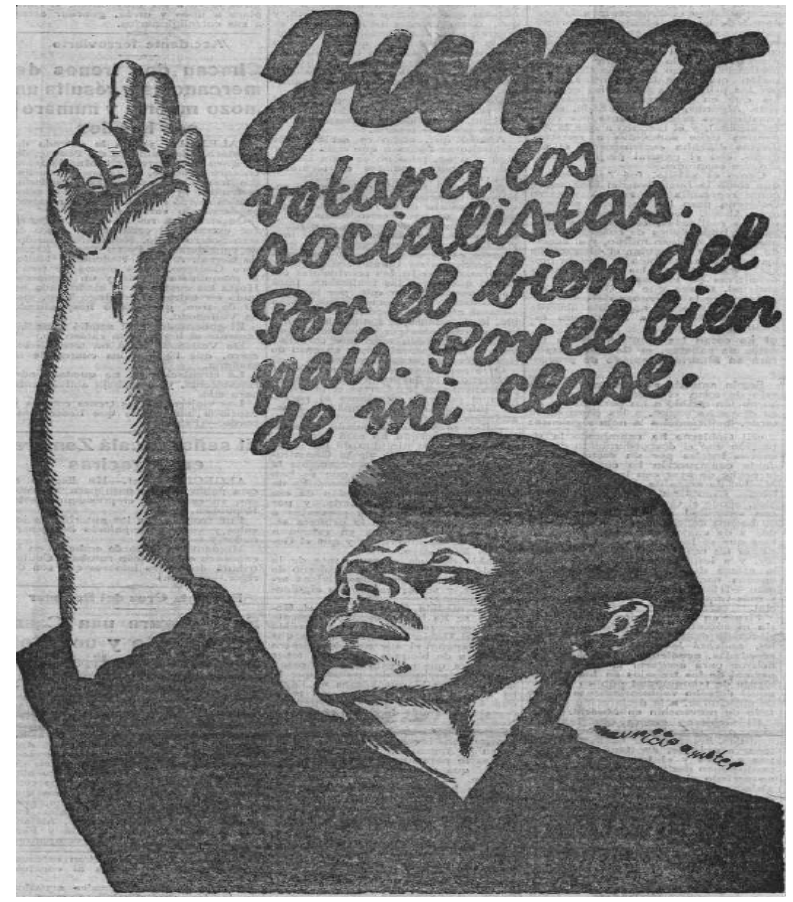

Imagen 1. Por el bien del país y de mi clase. Fuente: Fundación Pablo Iglesias.

\section{Mujeres, socialismo y nación}

Por último, si hasta aquí se ha intentado poner de manifiesto la combinación entre identidad de clase e identidad nacional llevada a cabo por el socialismo, las elecciones de noviembre impulsaron la voluntad de movilización femenina, lo que puso de manifiesto la convivencia en el socialismo de modelos de género tradicionales

67 "Un interesante discurso de Fernando de los Ríos", El Socialista, 28 de enero de 1936.
68 Prieto, Indalecio: Siento a España... 
y propuestas políticas y de identidad igualitarias y feministas. Así, por un lado, el Partido Socialista se dirigió preferentemente a una mujer ideal definida por un rol familiar y reproductivo ${ }^{69}$. En palabras de un asiduo colaborador de un semanario de Linares (Jaén),

Vosotras sois la sonrisa que nos anima, la palabra que nos conforta, el hogar cariñoso (...). Sois la madre que veneramos, la esposa a quien queremos, la hermana a quien amparamos, la hija que es nuestro orgullo, nuestra alegría, carne de nuestra carne. La novia, la madre futura de nuestros hijos, compañera un día de nuestro vivir $^{70}$.

De este modo, la propaganda socialista llamaba a las mujeres a ejercer el derecho de sufragio como madres y esposas de obreros, pero no en tanto que trabajadoras ${ }^{71}$. Los lemas más repetidos demandaron el voto femenino en solidaridad con los maridos y por el futuro de los hijos ${ }^{72}$. Así, desde El Socialista se conminaba a las mujeres proletarias a combatir como madres, esposas e hijas de proletarios; era necesario votar a los socialistas para asegurar el futuro de los hijos, que eran un "sagrado deber" para las mujeres ${ }^{73}$.

Por otro lado, los socialistas entendían merecer el voto de las mujeres gracias a su papel en la concesión del sufragio femenino. En este sentido, desde el socialismo se desplegaron discursos que reclamaban la ciudadanía femenina como un derecho propio y exhortaban a las mujeres a actuar de acuerdo con sus intereses como colectivo. Este sería el caso de María Cambrils, quien, tras negar la vinculación femenina con el catolicismo conservador, sostenía que el socialismo había conseguido la "igualdad de derechos y de deberes sociales para los dos sexos", por lo cual el interés de las mujeres era votar en sentido socialista ${ }^{74}$.

En una dirección similar, cabe destacar el mitin protagonizado por las socialistas Carmen del Barrio, María Lejárraga y Margarita Nelken en la Casa del Pueblo de Madrid. Las propagandistas se dirigieron a las mujeres como colectivo distintivo, tanto a las proletarias como a las de clase media, y pidieron el voto para el Partido Socialista como motor de la emancipación femenina y de una mayor igualdad social. Sin dejar de aludir a la maternidad como característica propiamente femenina, desde

69 La vinculación de las mujeres al espacio doméstico y familiar, no obstante, fue una vía de movilización femenina a favor del socialismo y permitía extender el rol doméstico a la esfera social para, desde el movimiento feminista, dignificar la maternidad. Aguado, Ana: "Feminismo socialista y/o socialismo feminista: María Cambrils", Arenal, 10-2 (2003), pp. 243-254; Aresti, Nerea: "Cuestión de dignidad. Género, feminismo y culturas políticas", en Carlos Forcadell y Manuel Suárez Cortina (coords.): La Restauración y la República, 1874-1936, Zaragoza, Marcial Pons/PUZ, 2015, pp. 85-110.

70 “AA nuestro lado mujeres!”, Justicia (Linares), 11 de noviembre de 1933.

71 Aguado, Ana: "República, democracia y pensamiento igualitario en la cultura socialista", en Aurora Bosch, Teresa Carnero y Sergio Valero (eds.): Entre la reforma y la revolución. La construcción de la democracia desde la izquierda, Granada, Comares, 2013, pp. 143-159. Tanto para estas elecciones como para las de 1936, de Luis, Francisco: "Familia, matrimonio y cuestión sexual en el socialismo español (1879-1936)", en Francisco Javier Lorenzo (ed.): La familia en la historia, Salamanca, Ediciones Universidad de Salamanca, 2009, pp. 261-291.

72 Diferentes carteles en El Socialista explotaban aquel recurso. Ente otros, véase los números de 27 de octubre y 5 y 6 de noviembre de 1933.

73 "El deber de la mujer proletaria", El Socialista, 3 de noviembre de 1933.

74 "El voto femenino", El Popular (Gandía), 26 de octubre de 1933. María Cambrils contaba ya con una amplia trayectoria de militancia socialista y activismo feminista; a tal efecto véase Solbes, Rosa, Aguado, Ana y Almela, Joan Miquel: María Cambrils. El despertar del feminismo socialista (biografía, textos y contextos), València, PUV, 2015 
el interior de la cultura política socialista aquellas mujeres apelaron a la condición de ciudadanas, proletarias y mujeres en general para movilizar el voto favorable al socialismo en defensa de sus intereses.

Sin embargo, más allá de las distintas formas de interpelación a -y construcción de- las mujeres, interesa destacar que en todos los casos la población femenina recibía el mensaje de ser "responsable de los destinos de España". En muchas ocasiones la vinculación de las mujeres a la nación no era tan directa como la de los varones, sino que se relacionaba con su condición de productoras de españoles y/o madres de España ${ }^{75}$, pero ellas también debían saber que la derecha no defendía convenientemente la patria porque "mandaron vuestros hijos a morir allende los mares defendiendo los intereses capitalistas" 76 .

Frente a los antimarxistas, las mujeres debían emular los mitos históricos de la lucha por la libertad nacional española:

Durante la guerra de la Independencia, (...) cada mujer hispana era una heroína: Agustina de Aragón... Durante el despotismo fernandino cada mujer liberal española era una mártir: Mariana Pineda... Durante las últimas etapas borbónicas -Cuba, Marruecos, etc...- en cada mujer española había una dolorosa, una santa mujer que sufría la tortura de ver a sus hermanos, a sus hijos, a sus maridos y a sus padres caer heridos, muertos o prisioneros por culpa de la impericia, de la ambición, de la maldad y de la chulería de los monárquicos... Durante la República -que ha acabado con todos esos dolores de la mujer española- cada mujer debe ser un voto salvador de la República ${ }^{77}$.

De este modo, por una parte, el socialismo recurría a la historia nacional como fuente de legitimidad para su propuesta política; por otro lado, se difundía un modelo de mujer española a imitar. Aunque el sufragio femenino suponía una novedad en las elecciones legislativas, la vocación de movilización femenina unida a la invocación de referentes históricos nacionales y de género no lo sería tanto. Ya en la campaña de 1931 Hildegart Rodríguez había esgrimido las cuentas pendientes de las mujeres con la Monarquía y llamó a las mujeres a repetir la defensa de España llevada a cabo por "nuestra heroica Agustina de Aragón" frente a "la invasión extranjera"78.

Esto indicaría que las demandas feministas construidas al abrigo de la cultura política socialista no estuvieron exentas de la asunción de una identidad nacional española ${ }^{79}$.

75 Especialmente interesante y representativo resulta en esta conceptualización el pensamiento de María Lejárraga estudiado en Aguado, Ana: "Cultura socialista, ciudadanía y feminismo en la España de los años veinte y treinta", Historia Social, 67 (2010), pp. 131-153 , y Capel, Rosa María: "Una mujer y su tiempo: María de la O Lejárraga de Martínez Sierra", Arenal, 19/1 (2012): pp. 5-46.

76 La crónica del mitin mencionado de donde provienen las citas en "En la Casa del Pueblo", El Socialista, 28 de octubre de 1933.

77 El Momento (Vivero), 1 de noviembre de 1933.

78 Rodríguez, Hildegart: "La mujer y el momento político", Renovación, 10 de abril del 1931.

79 Blasco, Inmaculada: "Mujeres y nación: ser españolas en el siglo XX”, en Javier Moreno y Xosé Manoel Núñez (eds.): Ser españoles..., pp. 168-206. 


\section{Segunda vuelta: la construcción antifascista}

Pasadas las elecciones, los socialistas denunciaron el falseamiento de la voluntad popular por las maniobras caciquiles ${ }^{80}$, mientras, como la Federación Socialista Valenciana, insistían en proclamarse "dignos representantes del pueblo a quienes al pueblo se deben y por el pueblo y con el pueblo lucharán" ${ }^{81}$. Pero, sin tiempo para mayores lamentos, la segunda vuelta electoral reclamaba un nuevo esfuerzo. En aquella ocasión y con la certeza de una representación parlamentaria muy inferior a la deseada, la propaganda socialista continuó impulsando la combinación del obrerismo con la defensa de España.

Así, en cierta manera, el Partido Socialista endureció los términos de sus discursos al predicar abiertamente la acción revolucionaria armada y tildar a sus rivales de fascistas. En este sentido, el 2 de diciembre la redacción de El Socialista subrayaba la perentoria necesidad de realizar la revolución para salvar a la clase obrera y evitar el triunfo del fascismo. El caso alemán evidenciaba que sin luchar el obrerismo estaba perdido ${ }^{82}$.

Estos planteamientos, poco sorprendentes en un partido obrerista defensor de la lucha de clases y el antifascismo, tenían un añadido menos ortodoxo, pues la proclamada revolución representaba la salvación de la nación. Desde su óptica, España era "un pueblo destruido por las oligarquías que durante siglos no hicieron otra cosa que empequeñecerlo geográficamente, despoblarlo, embrutecerlo y depauperarlo"; únicamente "un patriotismo de pacotilla" podía ocultar que "como nación (...) no representamos nada". La salvación nacional no podía llegar de la mano de "políticos conservadores o fascistas" que habían impuesto

Frenos espirituales desde el siglo XVI. Frenos materiales desde hace cuatro centurias. (...) El freno e impedir la expansión espiritual del español; malograr el desarrollo económico de España dentro de sus límites geográficos. No señores. Son ya demasiados frenos. España ha de salvarse. Pero del único modo que hará real esa salvación.

Por consiguiente, ya que el intento de regenerar la nación, de "crear una nueva España" había sido impedido,

Cerrada la senda de la legalidad y de la evolución, amenazado el proletariado con una regresión que haría de España nuevamente el botín de las antiguas castas insaciables, la Revolución social no es un capricho de utopistas, ni un anhelo de alienados, ni una ambición impracticable: es una necesidad histórica de la clase oprimida para salvarse y de España para existir como nación ${ }^{83}$.

De esta manera, la revolución socialista propugnada a finales del año 1933 era tan proletaria como nacional. Se trataba de evitar la derrota del proletariado y, al mismo

80 Entre otros, "Mil razones para ser optimista", El Socialista, 23 de noviembre de 1933.

81 "Para vergüenza de la República", El Socialista, 28 de noviembre de 1933.

82 "España, en la encrucijada dramática", El Socialista, 2 de diciembre de 1933. Este mensaje se reforzaba con un cartel que llamaba a pisar fuerte sobre el fascismo, encubierto y declarado, el 3 de diciembre de 1933.

83 Ambas citas en “¡Salvémonos y salvemos a España!”, El Socialista, 3 de diciembre de 1933. 
tiempo, acabar con la decadencia nacional -fechada, de acuerdo con la narración histórica nacional liberal-progresista y republicana, a principios de la época Moderna ${ }^{84}$ y garantizar la existencia de España como nación. Al fin y al cabo, si la clase obrera y el socialismo representaban los intereses de la nación contra el falso patriotismo, aquella era una construcción lógica y pertinente.

En buena medida, la segunda vuelta electoral, como colofón de la propaganda realizada en los meses anteriores, concentró la idea de la unión entre obrerismo y nación que el socialismo venía construyendo con anterioridad. La ansiada regeneración de España solo llegaría mediante el triunfo del socialismo marxista revolucionario, pues únicamente este desbancaría a los opresores de la nación de su posición de poder e iniciarían el camino de la realización patria. La clase y la nación, de nuevo, compartían objetivos sin entrar en colisión.

Asimismo, el repertorio discursivo puesto en escena apunta a la posible construcción del antifascismo desde el interior de la narrativa nacional. El discurso histórico nacional de raíz liberal-progresista y republicano reapropiado por el PSOE había tenido una destacada presencia en el contexto electoral de 1931. Entonces, el derrocamiento de la Monarquía se insertaba en una narración historicista que lo convertía en la recuperación de la libertad nacional perdida frente al absolutismo austríaco y borbónico ${ }^{85}$. La historia de lucha por la libertad y la afirmación de la auténtica personalidad de España funcionó como marco de significado tanto en 1931 como en 1933.

Llegados a la campaña de febrero de 1936 y mediante la inclusión del fascismo en una historia nacional de largo recorrido sobre la oposición entre el progreso y la reacción, los socialistas pudieron hacer del antifascismo un referente de defensa del movimiento obrero frente a sus enemigos de clase, pero también de sostenimiento de su idea de España. No se trata de una hipótesis aventurada, pues dicha dinámica ha sido detectada para el caso del antifascismo y el socialismo franceses ${ }^{86}$.

\section{Conclusiones}

Como balance final, si se recuperan las preguntas iniciales sobre la posible contribución socialista en el proceso de construcción de la identidad nacional española, es posible afirmar que el PSOE desplegó su discurso desde el interior de la identidad nacional española. En buena medida, la dialéctica de la lucha de clases, del combate entre marxismo y antimarxismo, se enunció a través de la identificación del socialismo con la defensa de los intereses nacionales, equiparados plenamente con los obreros. De este modo, el camino hacia el socialismo habría de suponer el triunfo de España, según era entendida desde la cultura política socialista. Por consiguiente,

84 Las coincidencias entre el discurso histórico socialista y el liberal progresista y republicano en de Luis, Francisco: "España en el discurso historiográfico socialista del primer tercio del siglo XX", en Pere Gabriel, Jordi Pomés y Francisco Hernández Gómez (eds.): «España Res publica». Nacionalización española e identidades en conflicto (siglos XIX y XX), Granada, Comares, 2013, pp. 407-426.

85 Entre otros, véase los mítines reseñados en "En el cinema Castilla", El Socialista, 7 de abril de 1931 y "En el Puente de Vallecas", El Socialista, 10 de abril de 1931.

86 Vergnon, Gilles: L'antifascisme en France, de Mussolini à Le Pen, Bonchamp-Lès Laval, Presses Universitaires de Rennes, 2009. Una contribución más reciente en Chambarlhac, Vincent y Hohl, Thierry: 1934-1936. Un moment antifasciste, Éditions la Ville brûle, Paris, 2014. Para el caso español, García, Hugo: "Was there an antifascist culture in Spain during the 1930s?", en Hugo García et alii (eds.): Rethinking antifascism. History, memory and politics, 1922 to the present, Nueva York, Berghahn Books, 2016, pp. 92-113. 
cabe sostener la participación socialista de la metanarrativa nacional y, por lo tanto, su contribución -intencionada o no- a la difusión de relatos de nación.

La formación discursiva del nacionalismo sirvió a los socialistas para ubicarse en el centro de la identidad nacional y, desde esta, atacar a sus rivales políticos. Así, el socialismo denunció la falta de patriotismo y/o condición extranjerizante de los sectores conservadores, católicos y monárquicos, a los cuales consideraba dominadores de una nación española oprimida secularmente, por lo que se erigía en continuador de las luchas por la libertad nacional. En aquella operación la apelación al pueblo como sujeto de acción y encarnación de la nación jugó un rol destacado, pero su lugar pudo ser ocupado por la clase obrera sin alterar la manifiesta adscripción nacional del socialismo. Si la idea de comunidad popular estaba en proceso de disgregación por aquellas fechas a favor de otras identidades como la clase ${ }^{87}$, la idea de España no perdía su relevancia en el vocabulario socialista.

El discurso del socialismo presentaba a España como comunidad política y unidad cultural e histórica conectada, además, a la esfera internacional. En efecto, el internacionalismo obrero suponía un componente propio de la cultura política socialista que se armonizó con la defensa de la nación, sin contradicción aparente desde su punto de vista. El internacionalismo socialista tomaba como punto de partida la nación, en tanto elemento natural definido por unos rasgos y genio distintivo. Desde el respeto y defensa de la propia personalidad nacional se pretendía aspirar a la fraternidad universal. De esta manera, el discurso de España del socialismo se convertía en una formulación compleja -asumida, no obstante, con naturalidad por parte socialista- que unía la clase a la nación y esta al ámbito de la humanidad.

Asimismo, aquel discurso disponía una vinculación nacional femenina a partir de la condición reproductiva biológica e ideológica de la nación ${ }^{88}$. La función maternal, de productora y educadora de individuos nacionales -y obreros-, fue la vía más común para vincular a las mujeres a la esfera nacional, aunque esto no impedía la existencia de propuestas discursivas que ligaban las mujeres a la nación desde la idea de una ciudadanía igualitaria.

En último lugar, el antifascismo que empezaba a ocupar un espacio creciente en el vocabulario socialista pudo incorporarse a $-\mathrm{y}$ reforzar- la lectura nacional de dos Españas enfrentadas que alimentó el conjunto de las campañas electorales socialistas. Como la revolución obrera, el antifascismo también se pudo conjugar mediante el repertorio discursivo y simbólico nacional, de lo que quedó buena muestra ya en el contexto de la Guerra Civil.

Por lo tanto, en el caso del socialismo español parece acertado asumir la idea lanzada por Robert Stuart, de acuerdo con la cual la nación se convirtió en matriz de significado donde las modernas ideologías -y entre ellas el socialismo- han competido para ser hegemónicas ${ }^{89}$. Dentro de esa esfera, los socialistas pugnaron por apropiarse el interés y la representación de la nación, conseguir una legitimidad política que no le proporcionaba el discurso de clase $y$, simultáneamente, deslegitimar a sus rivales como el otro. Como cabría esperar, desde el socialismo aquellos discursos sobre la

87 Cruz, Rafael: En el nombre..., pp. 62-67.

88 Sobre las diferentes categorías mediante las cuales las mujeres participan en la construcción de la comunidad nacional, Yuval-Davis, Nira: Gender \& nation, London, Sage, 1997.

89 Robert Stuart: Marxism and national identity. Socialism, nationalism, and National Socialism during the French fin de siècle, Albany, State University of New York Press, 2006, p. 84. 
nación se empapaban de los principios de la lucha anticapitalista internacionalista, lo cual no oscurecía en ningún caso el contenido nacional de sus discursos y objetivos.

Finalmente, no se debe desdeñar la importancia de estos discursos en la construcción de la identidad nacional española. Las campañas electorales intensificaron la propagación de discursos políticos entre la población a través de la palabra escrita y hablada. Junto a los diagnósticos sobre los problemas y soluciones de la realidad sociopolítica, la sociedad era expuesta a definiciones de la identidad colectiva. Por consiguiente, los procesos de difusión de las identidades políticas pudieron permitir la reproducción de identidades no necesariamente contrapuestas ni excluyentes como la nacional, la de clase o la de género. Tal como se ha recordado recientemente, las culturas políticas -y entre ellas las de la izquierda obrera- pudieron tener una influencia decisiva en la nacionalización de las masas, ya que a través de sus discursos, desde sus respectivos idearios, propagaron distintas ideas de nación ${ }^{90}$. Según se ha intentado mostrar, en el caso del socialismo español al mismo tiempo que sus bases recibían la doctrina y principios de acción socialistas, estas eran interpeladas como parte de una determinada comunidad nacional asumida como propia.

\section{Referencias bibliográficas}

Aguado, Ana: "Feminismo socialista y/o socialismo feminista: María Cambrils". Arenal, 10 (2003), pp. 243-254.

- "Cultura socialista, ciudadanía y feminismo en la España de los años veinte y treinta", Historia Social, 67 (2010), pp. 131-153.

- "República, democracia y pensamiento igualitario en la cultura socialista", en Aurora Bosch Teresa Carnero y Sergio Valero (eds.): Entre la reforma y la revolución. La construcción de la democracia desde la izquierda, Granada, Comares, 2013, pp. 143-159.

Álvarez Junco, José: "En torno al concepto de «pueblo». De las diversas encarnaciones de la colectividad como sujeto político en la cultura política española contemporánea", Historia Contemporánea, 26 (2004), pp. 83-94.

Andreu, Mariano: Alicante en las elecciones republicanas. 1931-1936, Alicante, Universidad de Alicante, 1985.

Archilés, Ferran: “Lenguajes de nación. Las «experiencias de nación» y los procesos de nacionalización: propuestas para un debate", Ayer, 90 (2013), pp. 91-114.

Aresti, Nerea: "Cuestión de dignidad. Género, feminismo y culturas políticas", en Carlos Forcadell y Manuel Suárez Cortina (coords.): La Restauración y la República, 18741936, Zaragoza, Marcial Pons/PUZ, 2015, pp. 85-110.

Aróstegui, Julio: Largo Caballero. El tesón y la quimera, Barcelona, Debate, 2013.

Bécarud, Jean: La Segunda República española, Madrid, Taurus, 1967.

Berger, Stefan y Smith, Angel: "Between Scylla and Charybdis: nationalism, labour and ethnicity across five continents, 1870-1939", en Stefan Berger y Angel Smith (eds.): Nationalism, Labour and ethnicity 1870-1939, Manchester, Manchester University Press, 1999, pp. 1-30.

90 Archilés, Ferran: "Lenguajes de nación. Las «experiencias de nación» y los procesos de nacionalización: propuestas para un debate", Ayer, 90 (2013), pp. 91-114; García Carrión, Marta: "Cultura nacional y nacionalismo español", en Carlos Forcadell y Manuel Suárez Cortina (coords.): La Restauración y ..., pp. 169198. 
Berger, Stefan: "Narrating the Nation: historiography and other genres", en Stefan Berger, Linas Eriksonas y Andrew Mycock (eds.): Narrating the nation. Representations in History, Media and the Arts, Oxford, Berghan Books, 2008, pp. 1-16.

Blasco, Inmaculada: "Mujeres y nación: ser españolas en el siglo XX", en Javier Moreno y Xosé Manoel Núñez (eds.): Ser españoles. Imaginarios nacionalistas en el siglo XX, Barcelona, RBA, 2013, pp. 168-206.

Boyd, Carolyn P.: Historia Patria. Política, historia e identidad nacional en España: $1875-$ 1975, Barcelona, Pomares-Corredor, 2000.

Cabrera, Miguel Ángel: "La crisis de la historia social y el surgimiento de una historia postsocial”, Ayer, 51 (2003), pp. 201-224.

Calhoun, Craig: Nacionalisme, Catarroja, Afers, 2008.

Callahan, Kevin: "Performing Inter-Nationalism in Stuttgart in 1907: French and German Socialist Nationalism and the Political Culture of an International Socialist Congress", International Review of Social History, 45 (2000), pp. 51-87.

Capel, Rosa María: "Una mujer y su tiempo: María de la O Lejárraga de Martínez Sierra", Arenal, 19/1 (2012): pp. 5-46.

Casanova, Julián: República y guerra civil, Barcelona, Crítica/Marcial Pons, 2007.

Chambarlhac, Vincent y Hohl, Thierry: 1934-1936. Un moment antifasciste, Paris, Éditions la ville brûle, 2014.

Cruz, Rafael: "La cultura regresa al primer plano", en Rafael Cruz y Manuel Pérez Ledesma (eds.): Cultura y movilización en la España contemporánea, Madrid, Alianza, 1997, pp. 13-34.

- El arte que inflama. La creación de una literatura política bolchevique en España. 19311936, Madrid, Biblioteca Nueva, 1999.

- En el nombre del pueblo. República, rebelión y guerra en la España de 1936, Madrid, Siglo XXI, 2006.

- Una revolución elegante. España, 1931, Madrid, Alianza Editorial, 2014.

De Luis, Francisco: "Familia, matrimonio y cuestión sexual en el socialismo español (18791936)", en Francisco Javier Lorenzo (ed.): La familia en la historia, Salamanca, Universidad de Salamanca, 2009, pp. 261-291.

— "España en el discurso historiográfico socialista del primer tercio del siglo XX", en Pere Gabriel Jordi Pomés y Francisco Hernández (eds.): «España Res publica». Nacionalización española e identidades en conflicto (siglos XIX y XX), Granada, Comares, 2013, pp. 407-426.

Del Rey, Fernando: Paisanos en lucha. Exclusión politica y violencia en la Segunda República española, Madrid, Biblioteca Nueva, 2008.

— "La República de los socialistas", en Fernando Del Rey (dir.): Palabras como puños. La intransigencia política en la Segunda República española, Madrid, Tecnos, 2011, pp. 158-225.

Elorza, Antonio y Ralle, Michel: La formación del PSOE, Barcelona, Crítica, 1989.

Forcadell, Carlos: "Los socialistas y la nación”, en Carlos Forcadell, Ismael Saz y Pilar Salomón (eds.): Discursos de España en el siglo XX, València, PUV, 2009, pp. 15-34.

Forner, Salvador: Industrialización y movimiento obrero. Alicante 1923-1936, València, Alfons el Magnànim, 1982.

Fuentes, Víctor: La marcha al pueblo en las letras españolas: 1917-1936, Madrid, Ediciones de la Torre, 2006. 
García, Hugo: "Was there an antifascist culture in Spain during the 1930s?”, en Hugo García et alii (eds.): Rethinking antifascism. History, memory and politics, 1922 to the present, Nueva York, Berghahn Books, 2016, pp. 92-113.

García Carrión, Marta: “Cultura nacional y nacionalismo español”, en Carlos Forcadell, y Manuel Suárez Cortina (coords.): La Restauración y la República, 1874-1936, Zaragoza, Marcial Pons/PUZ, 2015, pp. 169-198.

Godicheau, François: 'L'existence et le nom du Front populaire comme enjeux d'interprétation et d'appropriation (1936-1938) ", Mélanges de la Casa de Velázquez, 41 (2011), pp. 1735.

— "Front Populaire, de la tactique cominternienne aux «politiques du peuple»", Bulletin d'Histoire Contemporaine de l'Espagne, 48 (2013), pp. 13-25.

Guerra, Daniel: "Socialismo y cestión nacional en la España de la Restauración (18751931)", Revista de Estudios Políticos, 137 (2007), pp. 183-216.

— Socialismo español y federalismo (1873-1976), Oviedo, KRK, 2013.

Hall, Stuart: "Who needs «identity»", en Stuart Hall y Paul Du Gay (eds.): Questions of cultural identity, Londres: Sage, 2005, pp. 1-17.

Holbraad, Castern: Internationalism and Nationalism in European Political Thought, Nueva York, Palgrave Macmillan, 2003.

Holguín, Sandie: República de ciudadanos. Cultura e identidad nacional en la España republicana, Barcelona, Crítica, 2003.

Juliá, Santos: "Un dualismo problemático. La herencia de Pablo Iglesias", Anthropos. Boletín de información y documentación, 45-46-47 (1985), pp. 176-180.

— Los socialistas en la política española, 1879-1982, Madrid, Taurus, 1997.

Macarro, José Manuel: Causas de la radicalización socialista en la II República”, Revista de Historia Contemporánea, 1 (1982), pp. 178-226.

— "Los socialistas y la revolución”, en Manuel Álvarez Tardío y Fernando Del Rey (eds.): El laberinto republicano. La democracia española y sus enemigos (1931-1936), Barcelona, RBA, 2012, pp. 75-100.

Mainer, José Carlos: La Edad de Plata (1902-1939). Ensayo de interpretación de un proceso cultural. Madrid, Cátedra, 1986.

Mateo, Miguel Ángel: "Fuentes y metodología para el estudio electoral de la II República", Ayer, 3 (1991), pp. 139-164.

Morales, Antonio, Fusi, Juan Pablo y De Blas, Andrés (dirs.): Historia de la nación y del nacionalismo español, Barcelona, Galaxia Gutenberg, 2013.

Preston, Paul: La destrucción de la democracia en España, Barcelona, Grijalbo Mondadori, 1978.

Radcliff, Pamela: "La representación de la nación. El conflicto en torno a la identidad nacional y las prácticas simbólicas en la Segunda República”, en Rafael Cruz y Manuel Pérez Ledesma (eds.): Cultura y movilización en la España contemporánea, Madrid, Alianza, 1997, pp. 305-325.

Ruiz-Manjón, Octavio: "La Segunda República española. Balance historiográfico de una experiencia democratizadora”, Ayer, 63 (2006), pp. 279-297.

Solbes, Rosa, Aguado, Ana y Almela, Joan Miquel: María Cambrils. El despertar del feminismo socialista (biografía, textos y contextos), València, PUV, 2015.

Somers, Margaret: "Deconstructing and reconstruting class formation theory: narrativity, relational analysis, and social theory", en John R. Hall (ed.): Reworking class, Ithaca, Cornell University Press, 1997, pp. 73-105. 
Souto, Sandra: "De la paramilitarización al fracaso: las insurrecciones socialistas de 1934 en Viena y Madrid", Pasado y Memoria. Revista de Historia Contemporánea, 2 (2003), pp. 193-220.

Stuart, Robert: Marxism and national identity. Socialism, nationalism, and National Socialism during the French fin de siècle, Albany, State University of New York Press, 2006.

Tusell, Javier: La Segunda República en Madrid: elecciones y partidos políticos, Madrid, Tecnos, 1970.

- Las elecciones del Frente Popular en España, Madrid, Cuadernos para el Diálogo, 1971.

Tusell, Javier, Ruiz-Manjón, Octavio, García, Genoveva: Las constituyentes de 1931, unas elecciones de transición, Madrid, Centro de Investigaciones Sociológicas, 1982.

Valero, Sergio: Republicanos con la monarquía, socialistas con la República. La Federación Socialista Valenciana durante la Segunda República y la Guerra Civil (1931-1939), València, PUV, 2015.

Vergnon, Gilles: L'antifascisme en France, de Mussolini à Le Pen, Bonchamp-Lès Laval, Presses Universitaires de Rennes, 2009.

Villa, Roberto: La República en las urnas. El despertar de la democracia en España, Madrid, Marcial Pons, 2011.

Yuval-Davis, Nira: Gender \& nation, London, Sage, 1997.

Winock, Michel: "Socialisme et patriotisme en France (1891-1894)", Revue d'Histoire Moderne et Contemporaine, 20 (1973), pp. 376-423.

Wodak, Ruth et alii: The discursive formation of national identity, Edinburgh, Edinburgh University Press, 1999 